\title{
LENGTH-GIRTH RELATIONS OF FISHES FROM A MEDITERRANEAN LAGOON SYSTEM
}

\author{
Dimitrios K. MOUTOPOULOS ${ }^{1 *}$, Nikolaos DIMITRIOU², Theocharis NYSTAS ${ }^{1}$, \\ and Constantin KOUTSIKOPOULOS ${ }^{3}$ \\ ${ }^{1}$ Department of Fisheries-Aquaculture Technology, TEI of Western Greece, Mesolonghi, Greece \\ ${ }^{2}$ Aqua Action Company, Mesolonghi, Greece \\ ${ }^{3}$ Department of Biology, University of Patras, Rio-Patras, Greece
}

Moutopoulos D.K., Dimitriou N., Nystas T., Koutsikopoulos C. 2017. Length-girth relations of fishes from a Mediterranean lagoon system. Acta Ichthyol. Piscat. 47 (4): 397-400.

\begin{abstract}
We estimated the relations between total length (TL) and opercular $\left(G_{\text {ope }}\right)$ and maximum $\left(G_{\text {max }}\right)$ girths, for the eight most representative lagoon fish species in Mesolonghi-Etolikon lagoons within 2015-2017 (June through December). The following species were studied: Chelon saliens (Risso, 1810); Chelon auratus (Risso, 1810); Chelon ramada (Risso, 1827); Mugil cephalus Linnaeus, 1758; Diplodus puntazzo (Walbaum, 1792); Diplodus sargus (Linnaeus, 1758); Sparus aurata Linnaeus, 1758; Dicentrarchus labrax (Linnaeus, 1758). For five of these species (C. saliens, $C$. auratus, C. ramada, $S$. aurata, and D. labrax) LGR estimates were not available. Results showed that both $G_{\mathrm{ope}}$ and $G_{\max }$ increased significantly linearly with TL for all studied species with all $r^{2}$ values being higher than 0.862 . When $G_{\max }$ values were plotted against TL for all species combined, two significant (ANCOVA, $P<0.05$ ) length-girth relations were identified corresponding to different body shapes. The implications of girth measurements for lagoon gear selectivity estimates are also discussed.
\end{abstract}

Keywords: fish girth, fish morphology, barrier traps, Mesolonghi-Etolikon lagoons, Greece

Species-specific length-girth relations (LGR) allow the computation of girth from length measurements, the latter of which are easier and less expensive to be obtained. Such relations are important for quantifying:

- Biological components (e.g., condition and swimming capability: Wootton 1999)

- Ecological traits (e.g., predator-prey relations and trophic level estimation: Stergiou and Karpouzi 2003; feeding guilds: Pet et al. 1995)

- Fisheries assessment procedures (e.g. fishing gear efficiency: Reis and Pawson 1999, Stergiou and Erzini 2002)

LGR have been studied for numerous marine (i.e., Malaysia: Matsushita and Ali 1997; Portuguese coast: Mendes et al. 2006; southern Portugal: Santos et al. 2006; Aegean Sea: Stergiou and Karpouzi 2003) or freshwater (i.e., Iraq: Jawad et al. 2009; Colombia: Tobes et al. 2016) species and their estimates have been demonstrated for most fisheries compartments. For instance, trawl and gillnet selectivity estimates may benefit from girth data (Matsushita and Ali 1997, Stergiou and Erzini 2002, respectively), because these corresponding estimates are based on the opercular and maximum girth relation with length. However, very few girth data exist for fish species inhabiting periodically the lagoon systems (i.e.,
Patos Lagoon in Brazil: Reis and Pawson 1999; Szczecin Lagoon in Poland: Psuty et al. 2007) and none of them relates to the Mediterranean lagoons, where the gear efficiency is mostly based on maximum girth (fish width).

In the majority of the Mediterranean lagoons (Cataudella et al. 2015) fisheries exploitation is conducted using permanent fishing devices made of reinforced concrete, the barrier traps that are installed at the interface between the lagoon and open sea. Fisheries based on seasonal on-going migrations of fry and adult fish species for spawning, foraging, and shelter between open sea and lagoons (Franco et al. 2010) during June to February (Katselis et al. 2003). The multispecies nature of the lagoon fisheries, which in turn implied the exploitation of numerous species with different growth, maturity, behaviour, and body shape are increasing the uncertainty on the determination of gear-specific efficiency.

The aim of the presently reported study was the estimation of LGR for eight fish caught in the MesolonghiEtolikon lagoon system. The following species were studied: Chelon saliens (Risso, 1810); Chelon auratus (Risso, 1810); Chelon ramada (Risso, 1827); Mugil cephalus Linnaeus, 1758; Diplodus puntazzo (Walbaum, 1792); Diplodus sargus (Linnaeus, 1758); Sparus aurata Linnaeus, 1758; Dicentrarchus labrax (Linnaeus, 1758). 
The studied species (Table 1) contribute more than 90\% to the fisheries landings in the studied area (Katselis et al. 2003). To our knowledge, LGR estimates have not existed worldwide for five of these species, the diadromous species of the family Mugilidae (C. saliens, C. auratus, and C. ramada), as well as for two sparids ( $S$. aurata and D. labrax).

Sampling was conducted in the barrier traps of the Mesolonghi-Etolikon lagoon system within JulyDecember of 2015 and 2016. The lagoon area covering $131.5 \mathrm{~km}^{2}\left(38^{\circ} 30^{\prime} \mathrm{N}, 21^{\circ} 05^{\prime} \mathrm{E}-30^{\circ} 15^{\prime} \mathrm{N}, 21^{\circ} 35^{\prime} \mathrm{E}\right)$ consists one of the largest lagoon systems in the Mediterranean representing approximately $42 \%$ of the total surface of the Greek lagoons (Koutrakis et al. 2007). Total length (TL) and body girth were measured to the nearest millimetre for 1168 individuals. Girth measurements were obtained using a digital calliper and were measured from the height and width of opercular $\left(G_{\text {ope }}\right)$ and of maximum $\left(G_{\max }\right)$ girths. The perimeter of the ellipse (where minor and major radii are the maximum height and width, respectively) was estimated for each of the above proxies using the formula proposed by Ramanujan in 1914 (Arfken and Weber 2000) and applied in similar studies (Tobes et al. 2016). This method is considered to be more accurate than the maximum circumference to estimate the true perimeter of the fish body (Arfken and Weber 2000). Then, LGR was estimated using least-square regression (Zar 1999). The intercepts and the slopes of the LGR for $G_{\text {ope }}$ and $G_{\max }$ were compared for between-species differences using analysis of covariance (ANCOVA) (Zar 1999).

The relations of $G_{\text {ope }}$ and $G_{\max }$ with TL for the eight species are summarised in Table 1. For all studied species, the slopes of all the regressions were significant $(P<$ 0.05 ) and maximum girth increased fastest in length than opercular. Both $G_{\text {ope }}$ and $G_{\max }$ were linearly related to TL and all $r^{2}$ values were higher than 0.862 , with the latter minimum observed for Mugil cephalus in the case of $G_{\text {ope }}-$ TL (Table 1). When $G_{\max }$ was plotted against TL for all studied species, two groups of species were significantly (ANCOVA, $P<0.05 ; F=89.57$ ) formed (Fig. 1A). In particular, the torpediforms of the family Mugilidae (i.e., Chelon auratus, Chelon ramada, Chelon saliens, and M. cephalus) and Dicentrarchus labrax clearly formed a separate group (group A, Fig. 1A) distinct from Sparidae species (i.e., Diplodus puntazzo, Diplodus sargus, and Sparus aurata: group B, Fig. 1A) that were characterised by deepest body height.

Due to the nature of the lagoons, which are acting as a nursery grounds for numerous fish species (Franco et al. 2010), data for the studied species usually did not include the very large-sized individuals (generally larger than $42 \mathrm{~cm}$ in our study). Thus, the use of the LGR presented here should be limited to the observed length ranges (Table 1). LGR is seasonally influenced by factors such as food availability, feeding rate, gonad development, and spawning frequency (Santos et al. 2006). Thus, the estimated relations should not be considered as mean annual values, as the samples were collected during the offshore species seasonal migration (June to January: Katselis et al. 2003).

Girth measurements are positively and linearly related to total body length (e.g., Karpouzi and Stergiou 2003) a fact that is in accordance with the LGR reported here. All species have shown a steeper relation for maximum, rather than for opercular girths, which is mostly occurred for such relations (e.g., Mendes et al. 2006), apart for few exceptions (e.g., Liza abu (Heckel, 1843): see Jawad et al. 2009). LGR are firstly presented for five out of the eight studied species, whereas LGR had previously been reported for Diplodus puntazzo and D. sargus in Portugal coasts (Santos et al. 2006) and for Mugil cephalus in south-western Australian estuaries (Yeoh et al. 2014).

Girth and length, along with other biological (e.g., fish behaviour) and technical (e.g., fishing techniques, gear construction and dimensions) components, strongly determine the size selectivity of passive fishing gears,

Table 1

Principal length-girth relations of eight fish species caught in the Mesolonghi-Etolikon lagoon system (2015-2016)

\begin{tabular}{|c|c|c|c|c|c|c|c|c|c|c|c|}
\hline \multirow{2}{*}{ Family/Species } & \multirow{2}{*}{$n$} & \multirow{2}{*}{$\mathrm{TL}_{\min }$} & \multirow{2}{*}{$\mathrm{TL}_{\text {max }}$} & \multicolumn{4}{|c|}{$G_{\mathrm{ope}}=a+b \mathrm{TL}[\mathrm{cm}]$} & \multicolumn{4}{|c|}{$G_{\max }=a+b \mathrm{TL} \quad[\mathrm{cm}]$} \\
\hline & & & & Relation & $\mathrm{SE}_{a}$ & $\mathrm{SE}_{b}$ & $r_{G 1}^{2}$ & Relation & $\mathrm{SE}_{a}$ & $\mathrm{SE}_{b}$ & $r_{G 2}^{2}$ \\
\hline \multicolumn{12}{|l|}{ Mugilidae } \\
\hline Chelon saliens $^{+}$ & 145 & 14.8 & 31.4 & $y=-1.218+0.572 x$ & 0.242 & 0.011 & 0.962 & $y=-2.621+0.694 x$ & 0.260 & 0.012 & 0.962 \\
\hline Chelon auratus $^{+}$ & 205 & 23.1 & 37.7 & $y=0.007+0.560 x$ & 0.231 & 0.008 & 0.958 & $y=-3.161+0.716 x$ & 0.310 & 0.011 & 0.952 \\
\hline Chelon ramada ${ }^{+}$ & 109 & 23.5 & 37.9 & $y=-0.513+0.613 x$ & 0.400 & 0.014 & 0.944 & $y=-3.287+0.800 x$ & 0.518 & 0.019 & 0.940 \\
\hline Mugil cephalus & 80 & 16 & 59.3 & $y=5.509+0.453 x$ & 0.761 & 0.020 & 0.862 & $y=-3.303+0.731 x$ & 0.548 & 0.015 & 0.969 \\
\hline \multicolumn{12}{|l|}{ Sparidae } \\
\hline Diplodus puntazzo & 156 & 10.0 & 22.0 & $y=-2.501+0.975 x$ & 0.217 & 0.017 & 0.963 & $y=1.765+1.045 x$ & 0.201 & 0.015 & 0.971 \\
\hline Diplodus sargus & 157 & 8.7 & 20.8 & $y=0.679+0.931 x$ & 0.338 & 0.023 & 0.915 & $y=1.980+1.051 x$ & 0.377 & 0.026 & 0.917 \\
\hline Sparus aurata $^{+}$ & 176 & 9.6 & 33.6 & $y=0.139+0.906 x$ & 0.302 & 0.014 & 0.967 & $y=-0.349+1.016 x$ & 0.445 & 0.021 & 0.944 \\
\hline \multicolumn{12}{|l|}{ Moronidae } \\
\hline Dicentrarchus labrax & 140 & 13.3 & 42.4 & $y=-1.427+0.724 x$ & 0.285 & 0.012 & 0.967 & $y=-1.917+0.778 x$ & 0.315 & 0.013 & 0.965 \\
\hline
\end{tabular}

$G_{\text {ope }}=$ girth behind the gill-cover, $G_{\max }=$ girth in front of the first dorsal fin, $\mathrm{TL}=$ total length, $\mathrm{TL}_{\min }=$ minimum length, $\mathrm{L}_{\max }=$ maximum length, $\mathrm{SE}_{a}=$ standard errors of intercepts $a, \mathrm{SE}_{b}=$ standard errors of slopes $b, R_{G 1}$ and $R_{G 1}$ are coefficients of determination of both length-girth relations, respectively; ${ }^{+}$denotes species for which length-girth relations were firstly presented worldwide with respect to lagoon systems. 
such as the barrier traps, which are mostly used in Greek lagoon fisheries (Koutrakis et al. 2007). These gears are harmonized to the multi-species nature of Greek lagoons (Koutrakis et al. 2007) with fish having different body shapes (i.e., Mugilidae, Sparidae, and Moronidae) and/ or similar body shapes but different length at maturity estimates (Chelon saliens and M. cephalus: 20 and $32.5 \mathrm{~cm}$, respectively: Froese and Pauly 2017). The identification of two significantly different (ANCOVA, $P$ $<0.05$ ) LGR (Fig. 1A) clearly revealed that the LGR of the studied fishes could be described by few generic LGR each corresponding to different body shapes (Karpouzi and Stergiou 2003).

The variability of the body shapes caught at the barrier traps hampers the efforts towards a multi-species management of the lagoon fishery. For instance, the maximum widths of Dicentrarchus labrax and Diplodus sargus (2.74 and $2.72 \mathrm{~cm}$, respectively) that were corresponding to their enforced "minimum conservation reference size" as stipulated by the new Common Fisheries Policy (Anonymous 2013) were larger when compared with the aforementioned ones for the other lagoon species (Fig. 1B), because of the more pronounced cylindrical shape and deepest body width, respectively. Thus, managing the selectivity of the barrier traps for avoiding catching undersized individuals of the above-mentioned
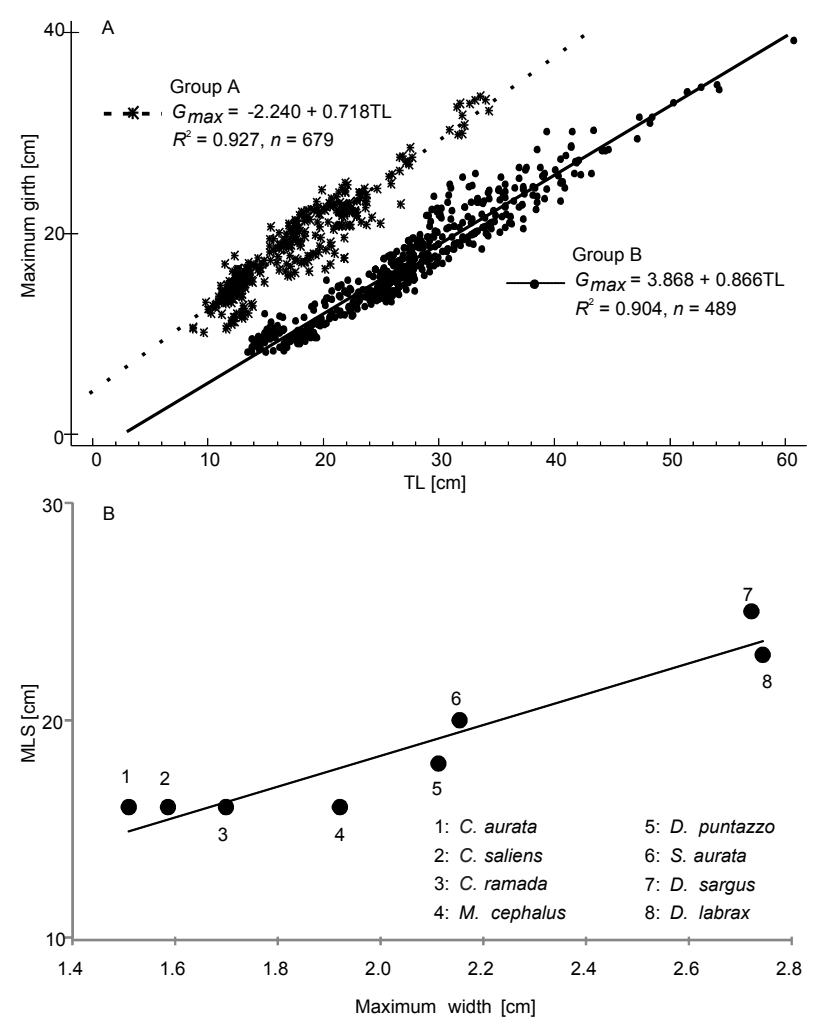

Fig. 1. Relations between TL and maximum girth $\left(G_{\max }\right)$; group $\mathrm{A}=$ Chelon saliens, $C$. auratus, $C$. ramada, Mugil cephalus and Dicentrarchus labrax; group B = Diplodus puntazzo, Diplodus sargus, and Sparus aurata; $r^{2}=$ coefficient of determination $(\mathbf{A})$; relation between minimum landing size (MLS) and maximum width (B) species would result in significant loss of commercial sizes of other fish species (Fig. 1B; Mugilidae and Sparus aurata). The existing problem concerns the concurrent presence of numerous species caught in the barrier traps at certain periods of the year, because for most species the time of the offshore migration is overlapped (September: D. puntazzo, D. sargus, M. cephalus; November: Chelon auratus, C. ramada, S. aurata; see Katselis et al. 2003).

In conclusion, girth estimates and more specifically the maximum width of a fish are expected to be equal to the width of the barrier traps than the total length in order to be caught in the traps. In this context, girth frequency distributions can be used as well for gear selectivity estimates, and thus both total length and girth parameters must be taken into account in gear size selectivity studies (for literature review see: Hamley 1975, Stergiou and Karpouzi 2003).

\section{ACKNOWLEDGEMENTS}

The presently reported study was partially funded by the Greek Operational Programme for the Fisheries Sector through the study: "Construction and evaluation of innovative fishing barrier traps in lagoons for the escapement of undersized fish to the coastal zone". The authors wish to express their gratitude to Mr Aristidis Mantzouratos for assisting in the fieldwork.

\section{REFERENCES}

Anonymous 2013. Regulation (EU) No. 1380/2013 of the European Parliament and of the Council of 11 December 2013 on the Common Fisheries Policy, amending Council Regulations (EC) No. 1954/2003 and (EC) No. 1224/2009 and repealing Council Regulations (EC) No. 2371/2002 and (EC) No. 639/2004 and Council Decision 2004/585/EC. Official Journal of the European Union L 354/22.

Arfken G.B., Weber H. 2000. Mathematical methods for physicists. 5th edn. Academic Press, London, UK.

Cataudella S., Crosetti D., Massa F. (eds) 2015. Mediterranean coastal lagoons: Sustainable management and interactions among aquaculture, capture fisheries and the environment. Studies and Reviews No. 95. General Fisheries Commission for the Mediterranean. FAO, Rome.

Franco A., Fiorin R., Zucchetta M., Torricelli P., Franzoi P. 2010. Flounder growth and production as indicators of the nursery value of marsh habitats in a Mediterranean lagoon. Journal of Sea Research 64 (4): 457-464.

DOI: $10.1016 /$ j.seares.2010.01.006

Froese R., Pauly D. (eds.) 2017. FishBase. [Version 02/2017] www.fishbase.org

Hamley J.M. 1975. Review of gillnet selectivity. Journal of the Fisheries Research Board of Canada 32 (11): 1943-1969.

DOI: $10.1139 / \mathrm{f} 75-233$

Jawad L.A., McKenzie A., Al-Noor S.S. 2009. Relationship between opercular girth, maximum girth and total length of fishes caught in gillnets in the 
estuarine and lower river sections of Shatt al-Arab River (Basrah Province, Iraq). Journal of Applied Ichthyology 25 (4): 470-473.

DOI: $10.1111 /$ j.1439-0426.2009.01254.x

Katselis G., Koutsikopoulos C., Dimitriou E., Rogdakis Y. 2003. Spatial patterns and temporal trends in the fishery landings of the Mesolonghi-Etoliko lagoon system (western Greek coast). Scientia Marina 67 (4): 501-511.

Koutrakis E.T., Conides A., Parpoura A.C., van Ham E.H., Katselis G., Koutsikopoulos C. 2007. [IV.5.] Lagoon fisheries resources in Hellas. Pp. 223-233. In: Papaconstantinou C., Zenetos A., Vasilopoulou A., Tserpes G. (eds.) State of Hellenic fisheries. Hellenic Centre for Marine Research, Athens, Greece.

Karpouzi V.S., Stergiou K.I. 2003. The relationships between mouth size and shape and body length for 18 species of marine fishes and their trophic implications. Journal of Fish Biology 62 (6): 1353-1365.

DOI: $10.1046 / j .1095-8649.2003 .00118 . x$

Matsushita Y., Ali R. 1997. Investigation of trawl landings for the purpose of reducing the capture of non-target species and sizes of fish. Fisheries Research 29 (2): 133-143.

DOI: $10.1016 / \mathrm{S} 0165-7836(96) 00534-6$

Mendes B., Fonseca P., Campos A. 2006. Relationships between opercula girth, maximum girth and total length of fish species caught in gillnet and trammel net selectivity surveys off the Portuguese coast. Journal of Applied Ichthyology 22 (3): 209-213.

DOI: $10.1111 / j .1439-0426.2006 .00734 . x$

Pet J.S., Pet-Soede C., van Densen W.L.T. 1995. Comparison of methods for the estimation of gillnet selection of tilapia, cyprinid and other fish species in Sri Lankan reservoir. Fisheries Research 24 (2): 141-164. DOI: 10.1016/0165-7836(94)00364-3
Psuty I., Draganik B., Blady W. 2007. Gillnet selectivity to roach, Rutilus rutilus, from the Szczecin Lagoon, Poland. Acta Ichthyologica et Piscatoria 37 (1): 17-23. DOI: 10.3750/AIP2007.37.1.03

Reis E.G., Pawson M.G. 1999. Fish morphology and estimating selectivity by gillnets. Fisheries Research 39 (3): 263-273.

DOI: $10.1016 / \mathrm{S} 0165-7836(98) 00199-4$

Santos M.N., Canas A., Lino P.G., Monteiro C.C. 2006. Length-girth relationships for 30 marine fish species. Fisheries Research 78 (2-3): 368-373. DOI: 10.1016/j.fishres.2006.01.008

Stergiou K.I., Erzini K. 2002. Comparative fixed gear studies in the Cyclades (Aegean Sea): Size selectivity of small-hook longlines and monofilament gillnets. Fisheries Research 58 (1): 25-40. DOI: $10.1016 / \mathrm{S} 0165-7836(01) 00363-0$

Stergiou K.I., Karpouzi V.S. 2003. Length-girth relationships for several marine fishes. Fisheries Research 60 (1): 161-168. DOI: $10.1016 / \mathrm{S} 0165-7836(02) 00077-2$

Tobes I., Miranda R., Gaspar S., Peláez-Rodríguez M. 2016. Biometric relations of freshwater fishes of the Suaza River (Huila Department, Colombia). Acta Ichthyologica et Piscatoria 46 (2): 137-140. DOI: 10.3750/AIP2016.46.2.11

Wootton R.J. 1999. Ecology of teleost fishes. 2nd edn. Kluwer Academic Publishers, Dordrecht, the Netherlands.

Yeoh D.E., Potter I.C., Hall N.G. 2014. Gill net selectivity of four teleost species in south-western Australian estuaries. Joint Congress of the Australian Society for Fish Biology and Australian Society for Limnology, 30 June-4 July 2014, Darwin, NT, Australia. [Poster presentation available at ResearchGate.]

Zar J.H. 1999. Biostatistical analysis. 4th edn. PrenticeHall, Upper Saddle River, NJ, USA.

Received: 16 May 2017 Accepted: 7 September 2017 Published electronically: 31 December 2017 